\title{
WANDERING MYTHS
}

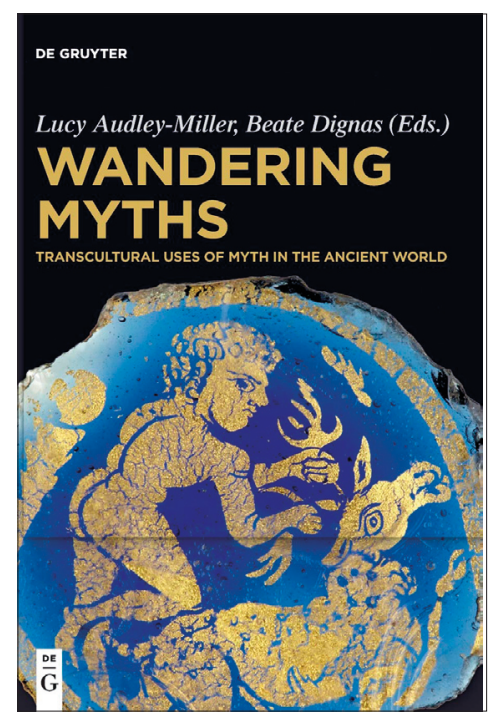

AUDLEY-MILLER, LUCY and DIGNAS, BEATE (eds.) (2018). Wandering Myths: Transcultural Uses of Myth in the Ancient World. Berlin-Boston: Walther de Gruyter GmbH. 481 pp., 127,71€ [ISBN 978-3-1104-1685-5].

\section{FERNANDO WULFF ALONSO \\ UNIVERSIDAD DE MÁLAGA \\ WULFF@UMA.ES}

EL LIBRO RESEÑADO ES EL FRUTO DE TRES TALLERES Y UN CONGRESO INTERNACIONAL en Oxford en 2014 alrededor de un tema fascinante: cómo los mitos se desplazan, viajan y son reutilizados, una perspectiva consistente con las líneas historiográficas dominantes que constatan la extrema permeabilidad de las sociedades antiguas mediterráneas y Próximo Orientales. Los mitos son un gran testigo de esto y lo que se hace con ellos permite entender mucho de los mismos mitos y de las sociedades que los adoptan por las formas en las que lo hacen.

Se entenderá que los catorce trabajos que forman su núcleo, producto de cuatro eventos distintos, no sean valiosos porque juntos aporten una búsqueda de aproximaciones comunes o, al menos, de una metodología o perspectivas participadas, sino por su variedad en una dirección de trabajo que, además, es una buena dirección. Cualquier 
estudioso o estudiante avanzado que esté interesado en particular en los caminos de los mitos griegos encontrará aquí una excelente ocasión para enriquecer perspectivas en muy diferentes direcciones.

El prefacio de las editoras es claro y se agradecen las referencias bibliográficas a las perspectivas que acompañan o abonan las búsquedas de perspectivas interculturales de los mitos. Como es frecuente, se pueden echar de menos referencias más hondas, por ejemplo, en lo referente a la revalorización de la parte romana de los préstamos, a las tradiciones culturales clasicistas que negaban creatividad a Roma y la valoraban en la medida en que adaptaban componentes griegos. O se podría apuntar que el tema de que los mitos son lo que son no porque vengan de unos orígenes prístinos sino por su, digamos, capacidad de adaptación, es importante, pero era parte ya del debate alrededor de Vernant y Vidal-Naquet hace casi medio siglo. Hay también en la introducción, como corresponde, una breve presentación de las aportaciones que siguen.

Uno sus aspectos más resaltables se encuentra en su final, en la p. XXII, cuando se afirma, tras este resumen de los aportes del libro: "The above overview of the volume should leave no doubt that the contributions in all three sections of the book critically address and respond to Robin Lane Fox's challenges in an equally challenging way. This is not, then, a book seeking to make bold statements about definitive origins, versions or clearly discernible developments of myths. Rather, our aim is to explore how stories 'wandered' and were subject to ongoing redefinition". El que las editoras dediquen previamente algo más de una página a plantear, y sobre todo, a puntualizar y a rebatir, la "Introducción" de Lane Fox lleva a la razonable pregunta del sentido de una introducción que ellas mismas sitúan como paradigma de aquello de lo que el libro se aleja.

Sea como fuere, la "Introducción" de Lane Fox abunda en lo planteado en su libro de 1988 (traducido en 2009, Héroes viajeros: los griegos y sus mitos. Barcelona: Crítica), en el que seguía lo que Tom Stinton había bautizado como el método "histórico-geográfico": los mitos se transmiten persona a persona y por contacto: viajeros, artistas, autores de mosaicos con sus libros de modelos, espectadores... y el papel en ellos de lo que llama Lane Stinton "creative misunderstanding". Destaca el rol de conquistas, sexo y misioneros, con ejemplos como Alejandro Magno creyendo encontrar evidencias del paso de Heracles en rasgos de pueblos de la India. Su ejemplo fundamental, con todo, son quienes habían sido objeto de su libro, los eubeos, que recogerían componentes neo-hititas en la zona del Monte Hazzi, cercana a Al Mina, alrededor de la primera mitad del s. VIII a.C. y los trasladarían por sus fundaciones mediterráneas hasta Italia y Sicilia. Dejando a un lado que aceptar este tipo de componentes no presenta ningún problema siempre que se justifique debidamente y no se convierta en el único camino de interpretación, no siempre la argumentación es cuidada. Defender que el nombre de una heroína de una saga en circasiano en el 
Cáucaso llamada Amezan reflejaría la forma indígena de la que los griegos derivarían la palabra "amazona" con el argumento de que a mediados del XIX, cuando se recoge, no había señales de influencia occidental o clásica (p. XXXVIII) significa ignorar en exceso la historia del Cáucaso. Como señalan las editoras tampoco es fácil de entender el tránsito en las páginas finales a los mitos de los troyanos en el contexto de los nostoi, esto es, el tránsito de hablar de viajeros concretos a mitos que hablan de viajes.

Es más útil el "Epilogo" de Robert Parker, que presenta de manera eficaz los textos, sin casi valoraciones, y hace dos observaciones útiles, una evidente, que los artículos pueden dividirse entre mitos que van a Grecia y mitos que salen de Grecia, y otra que debiera serlo: que la expansión de los mitos griegos deriva de su poder narrativo y de su enorme prestigio, un capital cultural que se difunde de múltiples maneras, una herencia compartida. Desde esta perspectiva, es difícil, podríamos añadir, llamar viajero ya a un mito en un sarcófago o mosaico del s. III en zonas que llevan mil años de presencia de cultura griega o quinientos de elaboraciones escritas griegas.

La primera parte del libro se dedica a tres trabajos bajo la rúbrica Part I: Changing Cultural and Mythical Landscapes in Anatolia. Son tres textos muy diferentes y no se puede menos que simpatizar con las dificultades de las editoras a la hora de organizar un material tan heterogéneo, incluso por encima del estupor de que el tercero de los trabajos se dedique centralmente a Arcadia y Chipre. Rutherford plantea un tema obligado y ya con muchos años de exploración: los paralelos entre los mitos de realeza y sucesión divina en Hesíodo y "El Canto de Kumarbi", encontrado en archivos hititas, pero muy conectado a historias hurritas, y las versiones del mito de Tifón, en particular las no hesiódicas, y otros mitos hititas. El interesante papel de la presencia en los mismos archivos de alrededor de veinte textos narrativos sobre divinidades que incluyen diversas importaciones nos sitúa ante la necesidad de entender que es imprescindible considerar el cruce en el mundo hitita no solo de los consabidos materiales babilonios, sino hurritas y luvitas, además de sirio-palestinos y quizás micénicos. La esquina noreste del Mediterráneo se muestra como un fértil lugar de intercambios desde el Bronce Final y hay que pensar en todo el conjunto de tradiciones en juego entonces, además de en las continuaciones y reelaboraciones en el I milenio a.C. que van a a parar a Hesíodo y el mundo heleno en general y en la complejidad de caminos y transmisores, que puede incluir vías anatólicas directas, además de las tradicionales de Chipre y Creta, y tanto en el primer como en el segundo milenio.

El trabajo de Catherine M. Draycott se dedica al Sarcófago de Polyxena y la tumba de Kizilbel, dos piezas halladas en Asia Menor y del tránsito entre los siglos VI y V a.C., es decir, en pleno mundo Aqueménida, las dos con representaciones mitológicas 
helenas nada usuales, una de ellas un sarcófago con magníficos relieves otra una tumba con pinturas en un estado, por lo demás, poco halagüeño. Las cuestiones tratadas se suceden y con mucha consistencia más allá de la clásica tarea de interpretar qué temas se representan: el significado que pueden haber tenido en ese contexto sepulcral y local, por ejemplo, desde la proyección de emociones de pérdida, o didácticas, a las imágenes que buscan proyectar quienes las encargan, incluyendo "estrategias de distinción", o el problema de qué papel cabe darles a las dos piezas para interpretar la historia del Asia Menor aqueménida. Los dos son muestras del enriquecimiento de elites en ese mundo en dos lugares alejados entre sí - la zona del Granicos y el Norte de Licia respectivamente - y con una presencia helena también muy diferente, pero en un contexto altamente interconectado. Los dos son fascinantes por razones propias. Qué hacen temas de muertes de princesas y lo que parece ser una boda en la tumba de un varón - según los huesos - y a qué identidad étnica se vincula el primero o el lugar del segundo en un espacio muy desconocido y en el que sorprende el uso del mito griego de manera tan masiva en sus pinturas parietales.

Tanja S. Scheer presenta un caso mas clásico, la historia de la fundación por el arcadio Agapenor de Paphos en Chipre en su nostos tras Troya. Sostiene que Ptolomeo de Megalópolis, gobernador ptolemaida de la isla a comienzos del siglo II a.C., literato y con raíces en Arcadia, tuvo que ver con la intensa renovación de este mito, que encontraría correspondencia también con su renovación en la arcadia Tegea. Es uno de los ejemplos en el libro de que sí hay artículos en los que sugieren "definitive origins, versions or clearly discernible developments of myths".

La segunda parte se abre con el artículo de Nancy T. de Grummond que presenta posibles precedentes del personaje de Mezencio en la Eneida a partir, sobre todo de un espejo etrusco de ca. 300 a.C. La propuesta de la autora de leer Mzntie es del todo arriesgada (p. 112) y nada excepto que parece un rey lo une al personaje representado. Por otra parte, tampoco nada en la imagen que parece representar a Aquiles vistiéndose lo asimila a Mezencio, lo que la autora sabe, pero contra-argumenta señalando el aspecto más fascinante de su artículo: la constatación de la existencia de muchas representaciones mitológicas etruscas, y de Praeneste, con imágenes y nombres de personajes que no cuadran, como Helena siendo parte de los tres personajes femeninos entre los que elige Alejandro, o Hércules aparentemente como matador del Minotauro. También cree ver un componente profético. A continuación, señala que hay un individuo real denominado Laucie Mezentie en una vasija del s. VII a.C. (en p. 120 de comienzos del VI), quizás de Caere, que puede apuntar a la existencia de una familia aristocrática o real con algún tipo de vinculación con la historia del rey Mezencio. Añade la existencia de una tumba en Roma de la segunda mitad del s. I a.C. en la que aparece Mezencio y quizás Ascanio, lo que vincula a versiones alter- 
nativas de Livio y Dionisio de Halicarnaso sobre Mezencio. Esta lectura le permite añadir un espacio más en lo que denomina "narrative stratigraphies" (p. 116), "a kind of stratigraphical chart" (p. 119), "stratigraphical model" (p. 12) que no es fácil de entender y que la autora en todo caso asimila de una manera no menos arriesgada a un modelo que construye para el tema de Cacu (Cacus en Virgilio) con menos espacio en el texto, pero quizás no con menos "bold statements".

Siguen dos análisis vinculando Italia y Grecia. Luca Giuliani, parte de la gran importancia de los componentes teatrales en las imágenes de vasijas apulias que trabajó Oliver Taplin a comienzos de los 1990s, quien sostiene que sin la presencia de representaciones de tragedias áticas en el siglo IV a.C. no se entienden. Giulaini cree más en el papel independiente de los textos. Y sostiene que la teatralidad de algunas escenas no implica teatro, sino formas teatrales convertidas en convenciones pictóricas, motivos estándar para contar historias. Contrasta representaciones cómicas, con signos de auténtica teatralidad, y trágicas, que pueden contener elementos de origen teatral, sin que impliquen repr esentaciones teatrales.

Katharina Lorenz se plantea las claves de la yuxtaposición de mitos griegos en las pinturas parietales pompeyanas, un viejo tema que desarrolla tratando de vislumbrar cambios en sus usos durante las diferentes fases de la pintura pompeyana. Ofrece una perspectiva convincente de cuándo aparece esta nueva práctica narrativa que hace recaer sobre el espectador la tarea de una exégesis más compleja a partir de generar una nueva forma de relato. Y se pregunta también por su posible crecimiento a partir de la tradición etrusca o del helenismo itálico o su novedad.

Los dos trabajos de Barbara E. Borg, y de B.C. Ewald sobre sarcófagos romanos y áticos, centrados en los siglos II-III ofrecen dos perspectivas igualmente interesantes. Yo destacaría del primero su reflexión metodológica e historiográfica. Es en los años 90 cuando se empieza a plantear el problema de la utilidad de este tipo de obras no para reconstruir obras griegas perdidas, sino, en la línea de entender el significado para los espectadores de las obras de arte, para analizar qué componentes de ellos hablaban de valores romanos y el proceso de lo que podríamos llamar, jugando con el célebre libro sobre la romanización de Atenas, la romanización del arte griego. Tan interesante como esto es su referencia a las proyecciones de modelos extraídos de la retórica, como "alegoría", usado generalmente con un alto nivel de impropiedad. La plasticidad de los mitos y los exempla que se proyectan con ellos centra un estudio donde se muestra el papel de los exempla maeroris, el dolor de la muerte, de los exempla mortalitatis y el triunfo en el siglo III de los exempla virtutis a identificar con la persona difunta, con el consiguiente cambio y reducción de temáticas. El trabajo de Edwards aborda, tras una sólida introducción a los sarcófagos áticos, la selección de mitos en ellos que, defiende, apunta a la conversión de la tumba en un heroon, a la 
heroización del difunto. Realiza también una rigurosa comparación sistemática entre los sarcófagos romanos y los áticos, definiendo dos "mitoesferas" diferentes.

Si es de lamentar la falta de una auténtica reflexión colectiva en el libro, también lo es que no haya ni siquiera en un caso tan claro, ni un amago de reflexión conjunta. Además, temas como los problemas de interpretación de los programas expuestos en el frecuentísimo caso de ausencia de huesos o de inscripciones que permitan saber de género, edad o identidades colectivas, también aparecen, como es lógico, en el trabajo de Draycott y una reflexión conjunta tampoco hubiera estado nada mal.

La abigarrada tercera parte comienza con un trabajo de Martin West que hubiera cuadrado muy bien al lado del de Rutherford, entre otras cosas para mostrar su contraste. West no sólo propone para las conexiones entre Gilgamesh y Homero un camino directo, sino que lo reconstruye: ni más ni menos que un poema, por supuesto, perdido, dedicado a Heracles. Así que genera tres columnas, una con las fuentes asiriobabilónicas, otra en medio con el poema de Heracles que imagina y una tercera con sus reflejos homéricos. West admite en su final la fragilidad de su intento. Es imaginativo y sin duda, un ejemplo más de que la de Lane Fox no es la única propuesta osada y unidireccional del libro.

Los trabajos de Pitches y Serida juegan con las relaciones entre mitos egipcios y griegos, cada uno desde un lado del juego. Pitcher muestra la muy griega y muy interesada lectura de los mitos de Osiris que lleva adelante Diodoro Sículo en su historia universal, un aspecto fascinante que es difícil que no recuerde, en su respectivo terreno, lo que significa el fenómeno de la creación de los cultos mistéricos, empezando por el de Isis, y que hay que entender en claves de radicales reutilizaciones. En este caso, Pitcher muestra la vinculación de sus usos al comienzo de la obra con el proyecto y las perspectivas historiográficas de un Diodoro nada polibiano. Rana Sérida apunta en sentido contrario. El ciclo de Inaros es un conjunto egipcio de historias fascinante en proceso de publicación que sitúan su argumento, la historia del guerrero Inaros, en época de la invasión asiria de Egipto, s. VII a.C, pero que se escriben a lo largo de los siglos posteriores, tienen un gran papel en el mundo egipcio bajo el poder griego y romano y aparecen en la famosa biblioteca del templo de Tebtunis del s. II. Es fascinante que sean tan distintos de la literatura egipcia tradicional. La autora defiende no ya una influencia directa de temas homéricos, sino el uso sistemático de éstos como modelos, aportando técnicas literarias, estrategias narrativas, fórmulas y otros componentes. El mito griego serviría aquí para que los sacerdotes construyeran en su propia lengua historias y memorias de resistencia que, curiosamente, sirven frente a griegos y romanos. A la espera de la publicación definitiva de los textos, el trabajo es una ventana abierta a un tema fascinante. Lo es también, a mi juicio, porque lecturas negativas de, por ejemplo, Heródoto hablando de la creencia en la 
transmigración en Egipto han sido puestas en duda con argumentos que no tienen en cuenta ni la complejidad de la historia egipcia en el I milenio a.C. ni las complejas respuestas espirituales e ideológicas a las que pueden dar lugar.

El texto de Rachel Wood se plantea el problema de seis representaciones escultóricas de Heracles en Irán, empezando con una de época seleúcida, finalizando con una del primer rey sasánida, y centrándose en particular en representaciones partas y de la Elymaida. Advierte la autora con razón de los peligros en la conocida asociación con Vahrām-Verethragna, de la necesidad de estudios específicos caso por caso, del riesgo de la sobre-interpretación, de la necesidad de estar seguro de que representaciones que podemos identificar llevan anexos componentes de la figura mítica en cuestión y de las lecturas distintas de piezas de unas culturas en otras. Llama la atención la carencia de la bibliografía básica sobre las representaciones de Heracles en el mundo grecorromano de los artículos del LIMC en adelante - y de los abundantes estudios de otras zonas del continente euroasiático por el que se extiende efectivamente la popularidad del héroe y que permitirían un marco comparativo y teórico más amplio.

Por último, el trabajo de Katherine Dunbabin se centra en el Levante grecoparlante entre los siglos II-V/VI y siguen los usos de Aquiles. Sobre la base del papel esencial de lo homérico en la cultura de la época, enfoca su trabajo en qué tipo de temas se eligen dentro de la amplitud de su repertorio mítico. Es un trabajo en el mejor sentido de la palabra, tradicional, riguroso, con referencias a todos los ámbitos de la cultura - pantomima, retórica, literatura panegírica y epigramática, otras artes... -, lleno de preguntas, pero también de respuestas. Historias conocidas en las que todos - artistas, patronos, público - esperaban la sorpresa y la originalidad en el enfoque de su presentación, muchas de ellas vinculadas a personajes femeninos - Tetis, Briseida, Deidamía, Pentesilea, Polixena -, otras a los componentes trágicos de su vida y de su muerte.

Un buen final para un libro con componentes tan interesantes que es imposible no lamentar la falta de una auténtica confluencia en el debate. 